\title{
Diagnosis and management of low-back pain in primary care
}

\author{
Adrian Traeger PhD, Rachelle Buchbinder PhD, Ian Harris PhD, Chris Maher PhD
}

— Cite as: CMAJ 2017 November 13;189:E1386-95. doi: 10.1503/cmaj.170527

$\mathbf{L}$ ow-back pain is the leading cause of disability worldwide. ${ }^{1}$ It is the second most common symptom-related reason for seeking care from a primary care physician. ${ }^{2}$ In Australia, low-back pain is the number one cause of early retirement and income poverty. ${ }^{3}$ Although most people will have low-back pain at some point, only around half will seek health care. ${ }^{4}$ In 2013, patients in the United States spent an estimated US\$87.6 billion on health services for low-back and neck pain (ranked third out of all health conditions), and this amount is increasing rapidly. ${ }^{5}$ When indirect costs (e.g., from lost productivity) are included, this estimate exceeds $\$ 100$ billion per annum. ${ }^{6}$

Despite increased spending on health services, patient outcomes have not improved, ${ }^{7}$ and global disability related to lowback pain has continued to increase. ${ }^{1}$ One explanation for this phenomenon could be that patients are receiving "low-value" health services - services that provide little to no benefit or cause harm ${ }^{8}$ - such as prescriptions for opioids, ${ }^{9}$ diagnostic imaging ${ }^{10}$ and spinal fusion surgery for patients with persistent low-back pain, that is, pain for more than 12 weeks. ${ }^{11}$ One survey of practice found $25 \%$ of patients with acute low-back pain, that is, pain for less than 12 weeks, were referred for imaging during the first visit to a family physician. ${ }^{12}$ In addition to problems of overuse, there is increasing evidence that physicians underuse treatments known to improve low-back pain. In a review of the medical records of 1000 adults in Australia (2009-2010) to measure compliance with expert consensus indicators representing appropriate care for 22 common medical conditions, only $21 \%$ of clinicians reported providing advice and reassurance ${ }^{13}-$ a recommendation given by all current major guidelines.

Two new guidelines - the UK National Institute for Health and Care Excellence clinical guideline for low-back pain and sciatica published in 2016 and a clinical practice guideline from the American College of Physicians published in 2017 - encourage a shift in thinking about the primary care management of low-back pain and support physicians in the provision of more appropriate care for their patients. ${ }^{14,15}$ We discuss the current recommendations and evidence base for management of low-back pain in primary care (Box 1). We focus on management options for nonspecific low-back pain and radicular pain or neurogenic claudication; these conditions comprise more than $95 \%$ of low-back pain seen in primary care ${ }^{2}$ and can be effectively managed in this setting.

\section{KEY POINTS}

- Most low-back pain with or without radicular pain or neurogenic claudication does not require immediate diagnostic imaging and can be managed in primary care.

- All patients with nonspecific low-back pain should be offered information on the nature of low-back pain, reassurance about the likely low risk of serious underlying disease and advice on evidence-based self-management.

- Patients with acute low-back pain who do not respond to initial management, or who are screened as being at high risk of a poor outcome with a validated prognostic screening tool, may benefit from nonpharmacologic treatments for pain relief, such as heat, massage or spinal manipulation.

- For patients with persistent low-back pain with no obvious pathology, nonpharmacologic treatments for pain relief, such as exercise programs, cognitive behavioural therapy, mindfulnessbased stress reduction, operant therapy, massage, spinal manipulation, acupuncture or multidisciplinary rehabilitation programs, may be of benefit.

- For patients with persistent low-back pain, there is limited evidence for the effectiveness of pharmacologic treatment and mixed recommendations from guidelines.

\section{Box 1: Evidence used in this review}

We used evidence provided in two clinical practice guidelines that were published in the past 12 months: the 2016 guideline from the National Institute for Health and Care Excellence in the United Kingdom ${ }^{14}$ and the 2017 guideline from the American College of Physicians in the United States with its accompanying evidence review. ${ }^{15}$ We prioritized the discussion of evidence from the 2017 guideline recommendations because they were the most recent. In addition, we searched the Cochrane Database of Systematic Reviews for reviews that were published by the Cochrane Back and Neck Review Group from database inception to Apr. 6, 2017. We found 17 review protocols and 51 reviews of low-back pain. We complemented this search with the most recent literature from our own collections. We used these articles to describe the evidence in areas where the 2017 American College of Physicians guideline did not describe the evidence base, the two recent guidelines had conflicting recommendations, and recent evidence may have superseded evidence provided in a guideline. We graded the quality of evidence that we located from other sources using the Grading of Recommendations Assessment, Development and Evaluation approach (http://gradeworkinggroup.org/). 


\section{How can physicians decide if low-back pain has a serious cause?}

Low-back pain is a common symptom and there are many possible causes. In primary care, low-back pain can be classified into one of four categories: a problem beyond the lumbar spine (e.g., kidney stones); a serious disorder affecting the lumbar spine (e.g., epidural abscess); low-back pain occurring with radicular pain (e.g., related to intervertebral disc herniation) or neurogenic claudication (e.g., related to central spinal canal stenosis); or nonspecific low-back pain. ${ }^{16}$ Nonspecific low-back pain - where a specific pathoanatomic diagnosis is not possible - accounts for about $90 \%$ of all low-back pain seen in primary care. ${ }^{17}$ The primary purpose of this initial classification is to identify the small number of patients with low-back pain who require specific treatments or urgent referral to a specialist to avoid serious consequences. In a longitudinal cohort study in primary care settings in Australia ( $n=1172$ ), less than $1 \%$ of patients were found to have a serious cause for their low-back pain (e.g., cancer, infection or fracture). ${ }^{18}$

A focused history and physical examination is used to identify those with a greater likelihood of serious disease or a specific cause of low-back pain (Box 2). All other cases are considered to be nonspecific low-back pain.

\section{Is it always necessary to determine a cause?}

Many physicians dismiss a diagnosis of nonspecific low-back pain ${ }^{23}$ and instead pursue specific diagnoses of the anatomic structures responsible for the pain. ${ }^{24}$ There are two problems with this approach. First, the tests used to identify anatomic sources of nonspecific low-back pain have unacceptably low validity, ${ }^{25}$ so the diagnoses are nominal. For example, the clinical utility of describing patients as having "neuropathic" back pain has not been established; screening questionnaires used to detect this condition have unclear evidence for validity, ${ }^{26}$ and there is evidence that drugs for neuropathic pain lack clinical effectiveness. One recent high-quality randomized controlled trial (RCT) involving patients with sciatica $(n=209)$ in Australia reported that pregabalin, a drug for neuropathic pain, was not effective for either acute or chronic radicular pain compared with placebo. ${ }^{27}$ Second, structural diagnoses encourage the use of structure-based treatments that have been shown to be ineffective. Despite evidence of their ineffectiveness, treatment with injections of anesthetics, corticosteroids, sclerosing agents, stem cells and blood products into back structures that are thought to be generating the pain waste billions of dollars each year. For example, almost 1 million lumbar facet injections were funded by the Centers for Medicare and Medicaid Services in the US in $2011 .{ }^{28}$

\section{Which patients require diagnostic imaging?}

Most patients who complain of low-back pain do not require diagnostic imaging immediately. Imaging is only indicated if a specific cause of low-back pain is suspected and timely diagnosis is critical to safe effective care..$^{29}$ If there is low suspicion of cancer or fracture, it may be reasonable to defer testing and start a trial of treatment. However, if there is any level of suspicion of cauda equina syndrome or an epidural abscess, immediate investigation is warranted given the serious consequences of delayed diagnosis. ${ }^{29}$ Contrary to common practice, patients with radicular pain or radiculopathy related to suspected disc herniation or neurogenic claudication related to suspected central spinal canal stenosis, do not need to be referred for immediate imaging, because the results will not change primary care management; the initial management of these conditions and nonspecific low-back pain are the same (Figure 1).

Some clinical guidelines encourage diagnostic imaging when one red flag is present (i.e., an alerting feature such as night pain). ${ }^{30}$ Although serious disease is uncommon, red flags may be common; therefore, this approach is unwise. For example, in a

Box 2: Alerting clinical features for specific causes of low-back pain*

\section{Serious spinal disease}

- New bladder or bowel disturbance, saddle numbness, lower motor neuron weakness (consider cauda equina syndromet)

- New onset of fever and history of intravenous drug use, spinal procedure, immunosuppression (consider vertebral infectiont)

- History of cancer that metastasizes to bone (e.g., breast, lung, prostate) (consider metastatic disease)

- History of osteoporosis, systemic steroid use, trauma, older age (more than 65 years of age) (consider vertebral fracture if multiple features present $)^{19}$

- Persistent symptoms (more than 12 weeks), age at onset is less than 45 years, inflammatory features (insidious onset, no improvement with rest, pain at night and/or early morning that improves with exercise or activity), peripheral manifestations (e.g., arthritis, enthesitis, uveitis, psoriasis) or family history of spondyloarthritis (consider axial spondyloarthritis) ${ }^{20}$

\section{Problem beyond the spine}

- Systemically unwell

- Nonmechanical pain (i.e., pain that is unrelated to movement)

- Hip joint signs (consider hip joint disease)

- Abdominal pulsations (consider abdominal aortic aneurysm) ${ }^{21}$

- Gynecologic, renal/urinary tract, gastrointestinal signs and symptoms (e.g., abdominal tenderness, hematuria) (consider visceral origin)

- Atherosclerotic risk factors, claudication (consider vascular origin)

Radicular pain or neurogenic claudication

- Leg pain in a spinal nerve distribution with or without low-back pain (consider radicular paint)

- Sensory loss, reduced reflex, myotomal weakness in spinal nerve distribution (consider radiculopathy $\uparrow$ )

- Bilateral buttock, thigh or leg pain, pseudoclaudication (consider central spinal canal stenosis† (e.g., age-related degenerative changes including degenerative spondylolisthesis)

*Adapted from the article by Atlas and Deyo. ${ }^{22}$

$\dagger$ These patients may not have low-back pain. Suspicion of cauda equina syndrome or vertebral infection requires urgent referral to a specialist. 
prospective longitudinal study involving 482 consecutive patients who attended a back pain triage clinic, 213 (44\%) reported night pain, yet none of the these patients had serious disease. ${ }^{31}$ In an Australian cohort of 1172 patients, ${ }^{18}$ where less than $1 \%$ of patients had a serious cause of the low-back pain, $80 \%$ had at least one red flag. This means that most red flags will be false positives. A Cochrane review of 24 red flags for malignant disease $^{32}$ found only one (previous history of cancer) that had acceptable diagnostic accuracy in patients with low-back pain. Decisions about further diagnostic work-up should be based on consideration of a combination of clinical features, the strength of clinical suspicion and the consequences of a delayed diagnosis. Clinical decision aids to support screening for serious disease have been developed; 33 however, these have not been evaluated in diagnostic studies. Many patients expect diagnostic imaging, ${ }^{34}$ and a clear explanation for not ordering immediate imaging should be provided. We have presented an example dialogue in Appendix 1 (available at www.cmaj.ca/lookup/suppl/ doi:10.1503/cmaj.170527/-/DC1).

\section{How should acute low-back pain be managed?}

Two recent changes to guidelines for acute low-back pain are important. First, nondrug options are preferred over pharmacologic pain relief for initial management of back pain. ${ }^{14,15}$ Second, a stratified approach to management based on scores from prognostic screening questionnaires rather than on response to initial management is recommended in the UK guideline. ${ }^{14}$ Guidelinecongruent management of acute low-back pain is summarized in Table 1. Key changes to management of low-back pain over the past 10 years are summarized in Appendix 2 (available at www. cmaj.ca/lookup/suppl/doi:10.1503/cmaj.170527/-/DC1).

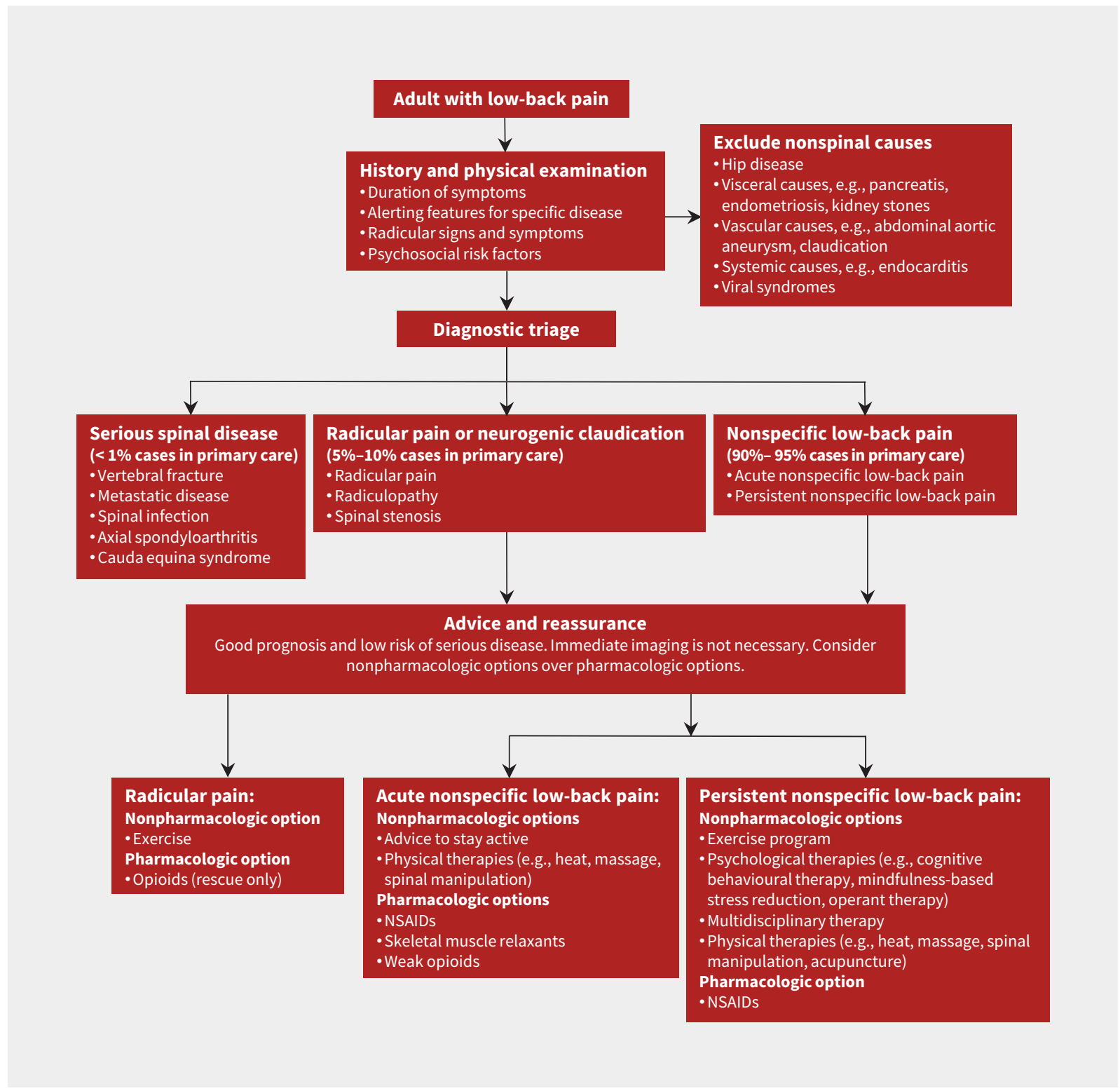

Figure 1: Diagnosis and management of low-back pain according to current clinical practice guidelines from the United Kingdom and United States. ${ }^{14,15}$ NSAID = nonsteroidal anti-inflammatory drug. 


\section{Nonpharmacologic treatments}

The recent guidelines recommend providing advice to stay active, and reassurance about the high chance of a good prognosis and the low chance of serious disease. ${ }^{14,15}$ We also suggest that physicians inform the patient that pain often recurs. Although nonpharmacologic treatment options may include massage or spinal manipulation, the US guideline qualified its recommendation for nonpharmacologic treatments by stating: "most patients with acute or subacute low back pain improve over time regardless of treatment." Acute episodes improve rapidly in the first two weeks; ${ }^{37}$ we suggest arranging a review within one to two weeks of initial presentation at a mutually agreed time. Timely review will allow physicians to assess progress toward recovery and the effectiveness of any initial treatments that are provided.

The evidence for treatment with spinal manipulation in patients with acute low-back pain that was considered for the US guideline was not strong: two RCTs $(n=292)$ showed a small effect on function and an unclear effect on pain compared with placebo spinal manipulation. ${ }^{15} \mathrm{~A}$ recent systematic review that included 15 RCTs $(n=1711)$ found moderate-quality evidence that, although it was no better than placebo spinal manipulation at reducing pain, spinal manipulation was associated with a small short-term reduction in pain compared with other treatments (around 10 points on a 100-point scale). ${ }^{38}$ Identified harms of spinal manipulation included a short-term increase in pain in $50 \%$ to $67 \%$ of patients. ${ }^{38}$

A systematic review that included 14 RCTs $(n=4872)$ of patient education interventions in primary care found strong evidence that patient education reduced psychological distress and use of health care related to low-back pain; ${ }^{39}$ yet, on its own, patient education did not improve pain or function in patients with acute low-back pain.

The US guideline suggested other nonpharmacologic options for initial management such as superficial heat and acupuncture. ${ }^{15}$ The guideline's evidence review concluded that there was low-quality evidence (two RCTs, $n=100$ ) for a small short-term effect of acupuncture on pain outcomes compared with placebo acupuncture. This contrasts with the UK guideline, which recommended that physicians not offer acupuncture to patients with low-back pain based on a lack of "compelling and consistent treatment specific effect." ${ }^{14}$ The UK guideline acknowledged that

Table 1: Recent guideline recommendations for management of acute nonspecific low-back pain

\begin{tabular}{|c|c|c|c|c|c|}
\hline \multirow[b]{2}{*}{ Type } & \multirow[b]{2}{*}{ Intervention } & \multirow{2}{*}{$\begin{array}{l}\text { Size of } \\
\text { effect* }\end{array}$} & \multirow[b]{2}{*}{ Quality of evidence* } & \multicolumn{2}{|c|}{ Endorsement } \\
\hline & & & & 2016 UK guideline ${ }^{14}$ & 2017 US guideline $\mathrm{e}^{15}$ \\
\hline \multirow[t]{7}{*}{ Nonpharmacologic } & $\begin{array}{c}\text { Advice to stay active v. bed } \\
\text { rest }\end{array}$ & Small & Moderate† (2 RCTs) $)^{35}$ & Yes & Yes \\
\hline & Massage v. sham treatment & Moderate & Low (2 RCTs) & $\begin{array}{c}\text { Yes, if part of an exercise } \\
\text { program }\end{array}$ & Yes \\
\hline & $\begin{array}{l}\text { Spinal manipulation v. } \\
\text { inert treatment }\end{array}$ & No effect & Low (3 RCTs) & $\begin{array}{c}\text { Yes, if part of an exercise } \\
\text { program }\end{array}$ & Yes \\
\hline & $\begin{array}{l}\text { Acupuncture } v \text {. sham } \\
\text { treatment }\end{array}$ & Small & Low (3 RCTs) & Do not offer & Yes \\
\hline & Heat v. sham treatment & Moderate & Moderate (4 RCTs) & No mention & Yes \\
\hline & Exercise v. usual care & No effect & Low (6 RCTs) & Yes & No mention \\
\hline & $\begin{array}{l}\text { Psychologically informed } \\
\text { physiotherapy v. usual care }\end{array}$ & No trials & N/A $†$ & $\begin{array}{l}\text { Yes, for those at high risk } \\
\text { of poor outcome }\end{array}$ & No mention \\
\hline \multirow[t]{5}{*}{ Pharmacologic } & NSAIDs v. placebo & Small & Moderate (5 RCTs) & Yes & $\begin{array}{l}\text { Yes, depending on } \\
\text { patient preferences } \\
\text { and drug risk profile }\end{array}$ \\
\hline & Muscle relaxants v. placebo & Small & Moderate (5 RCTs) & No mention & $\begin{array}{l}\text { Yes, depending on } \\
\text { patient preferences } \\
\text { and drug risk profile }\end{array}$ \\
\hline & Opioids v. placebo & No trials & N/A $†$ & $\begin{array}{l}\text { Yes, if NSAIDs are unsafe } \\
\text { or ineffective; weak opioid } \\
\text { only }\end{array}$ & Do not offer \\
\hline & Paracetamol v. placebo & No effect & Hight (2 RCTs) $)^{36}$ & Do not offer & Do not offer \\
\hline & $\begin{array}{l}\text { Systemic corticosteroids v. } \\
\text { placebo }\end{array}$ & No effect & Low (2 RCTs) & No mention & Do not offer \\
\hline
\end{tabular}

Note: GRADE = Grading of Recommendations Assessment, Development and Evaluation, N/A = No evidence from RCTs, NSAID = nonsteroidal anti-inflammatory drug, RCT = randomized controlled trial.

*Based on 2017 American College of Physicians guideline summary of evidence except where otherwise noted. Comparisons are to placebo, sham treatment, no treatment or usual care, and on short-term pain outcomes.

tOur summary of evidence used the GRADE approach. 
some studies have shown clinically important effects compared with usual care but also notes that they were short-term studies with possible contextual effects, such as those resulting from patients having positive expectations about the treatment or from receiving effective reassurance and emotional support. ${ }^{14}$ Superficial heat therapy was endorsed by the US guideline based on a Cochrane review that found moderate-quality evidence (two RCTs, $n=258$ ) for a moderate effect (about 17 points on a 100-point scale) on short-term pain outcomes compared with oral placebo or nonheated wrap. ${ }^{40}$

The US guideline found low-quality evidence (six RCTs: three from a 2005 Cochrane review $[n=491]$ and an additional three trials $[n=653]$ ) that exercise is not effective for acute low-back pain compared with usual care. ${ }^{15}$ The role for exercise in the prevention of pain recurrence after the patient has recovered was evaluated in a systematic review of 21 RCTs $(n=30850)$ that concluded there was low- to very low-quality evidence that exercise alone can reduce the risk of future episodes of low-back pain compared with no exercise (relative risk [RR] 0.65, 95\% confidence interval $[\mathrm{Cl}]$ 0.50-0.86). ${ }^{41}$

\section{Pharmacologic treatments}

Nonsteroidal anti-inflammatory drugs (NSAIDs) are the only pharmacologic option endorsed by both recent guidelines. ${ }^{14,15} \mathrm{~A}$ systematic review found high-quality evidence (five randomized trials, $n=814$ ) that NSAIDs provided a small effect on pain compared with placebo in patients with acute low-back pain (mean difference 6.4 points on a 100 -point scale, $95 \% \mathrm{Cl} 2.5-10.3) .{ }^{42}$ Harms of NSAIDs are well known; the US guideline found moderate-quality evidence (10 RCTs) for increased risk of adverse events such as abdominal pain, gastrointestinal bleeding and heartburn (RR 1.35, 95\% Cl 1.09-1.68). ${ }^{15}$ It recommended pharmacologic options only as second-line options and, in addition to NSAIDs, included the option of skeletal muscle relaxants.

A review that evaluated the efficacy and tolerability of muscle relaxants found good-quality evidence (five RCTs, $n=496$ ) that muscle relaxants provided clinically meaningful pain relief in patients with acute low-back pain (about 20 points on a 100-point scale) compared with placebo. ${ }^{43}$ However, the US guideline cited the following harms of using muscle relaxants based on evidence from eight RCTs: increased risk of dizziness, drowsiness and sedation (RR 1.50, 95\% Cl 1.14-1.98). Such harms are particularly relevant to consider when prescribing for certain groups with lowback pain (e.g., older adults).

\section{How should persistent nonspecific low-back pain be managed?}

\section{Nonpharmacologic treatments}

Important differences between management of persistent and acute low-back pain are summarized in Table 2, with evidencebased nonpharmacologic options for persistent low-back pain. Both the US ${ }^{15}$ and UK guidelines ${ }^{14}$ endorsed exercise programs, cognitive behavioural therapy and multidisciplinary therapy as treatment options for persistent nonspecific pain, none of which were recommended for acute low back pain. Evidence from
53 RCTs ( $n=5801)$ suggested that nonpharmacologic treatments (e.g., exercise, spinal manipulation, acupuncture, cognitive behavioural therapy), although traditionally thought to improve function but not pain, may provide modest effects on pain intensity, equivalent to those of popular pharmacologic options. ${ }^{47}$

Most nonpharmacologic treatments for persistent low-back pain are time and resource intensive, which limits their provision in primary care. In some countries, including Canada, these options may not be funded by public health services. Strategies to improve access to nonpharmacologic treatments, for example, through remotely delivered interventions or funding of allied health staff to provide treatments such as cognitive behavioural therapy in primary care, have not been researched extensively.

Physicians who recommend nonpharmacologic treatments for persistent low-back pain can use a "stratified" approach (i.e., allocate higher-intensity treatments to those patients at highest risk of poor outcomes - discussed in the "Who needs referral?" section) or a "stepped" approach (i.e., allocate higher-intensity treatments to those patients whose symptoms fail to respond to lowintensity treatments). The UK guideline endorsed the stratified approach (presumably because there is evidence of its effectiveness from one trial conducted in the UK ${ }^{48}$ ), whereas the US guideline described the traditional stepped approach. There is little evidence that compares the effectiveness and cost-effectiveness of these two strategies.

\section{Pharmacologic treatments}

Notable recent changes to recommendations regarding pharmacologic management of persistent low-back pain are summarized in Appendix 3 (available at www.cmaj.ca/lookup/suppl/ doi:10.1503/cmaj.170527/-/DC1). Similar to acute low-back pain, the only pharmacologic option endorsed by both recent guidelines for persistent low-back pain is use of NSAIDs. The previously mentioned systematic review investigated the effects of NSAIDs in patients with persistent low-back pain and found evidence from seven RCTs ( $n=2277$ ) that brief courses of NSAIDs had a small effect on pain compared with placebo (mean difference 11.1 points on a 100 -point scale, $95 \% \mathrm{Cl} 8.4-13.8) .{ }^{42}$ Nonsteroidal anti-inflammatory drugs should be confined to a brief course of less than two weeks in carefully selected patients with a favourable renovascular and gastrointestinal risk profile, given their potential harms. The UK guideline suggested ongoing monitoring of risk factors for patients taking NSAIDs and consideration of gastroprotection. Both guidelines specify that NSAIDs should be used for the shortest possible period. Use of acetaminophen, tricyclic antidepressants and benzodiazepines are discouraged in the management of persistent low-back pain. Unlike for acute low-back pain, there is insufficient evidence to support the use of muscle relaxants for persistent low-back pain. ${ }^{43}$

The UK and US guidelines differ regarding use of opioids. Although the UK guideline supported offering weak opioids to patients with acute low-back pain if NSAIDs are contraindicated, prescribing opioids for persistent low-back pain was discouraged. There are no placebo-controlled trials of opioids involving patients with acute low-back pain, only those with persistent low-back pain. ${ }^{9}$ The US guideline advised against 
prescribing opioids for acute low-back pain but to consider them as a last resort for patients with persistent low-back pain. A Cochrane review that included 15 RCTs $(n=5540)$ of moderate quality found evidence of pain reduction of about 11 points on a 100-point scale for use of opioids compared with placebo among patients with persistent low-back pain; ${ }^{44}$ however, many patients do not respond to, or tolerate, these drugs. A 2016 systematic review of 20 placebo-controlled RCTs ( $n=7925$ ) that evaluated opioids for persistent low-back pain reported that the median drop-out rate owing to adverse events or lack of efficacy was $50 \% . .^{9}$ The 2016 US Centers for Disease Control and Prevention guideline for prescribing opioids for chronic pain ${ }^{49}$ suggested that physicians should prescribe opioids only under the following circumstances: benefits are likely to outweigh the risks for a given patient; treatment with opioids is combined with nonpharmacologic and nonopioid pharmacologic therapy; and treatment goals, including a discontinuation plan, are established with the patient. The 2017 Canadian "Guideline for Opioid Therapy and Chronic Noncancer Pain" 50 provides strategies to minimize use

Table 2: Recent guideline recommendations for management of persistent nonspecific low-back pain

\begin{tabular}{|c|c|c|c|c|c|}
\hline \multirow[b]{2}{*}{ Management type } & \multirow[b]{2}{*}{ Intervention } & \multirow[b]{2}{*}{ Size of effect* } & \multirow{2}{*}{$\begin{array}{l}\text { Quality of } \\
\text { evidence* }\end{array}$} & \multicolumn{2}{|c|}{ Endorsement } \\
\hline & & & & 2016 UK guideline ${ }^{14}$ & 2017 US guideline ${ }^{15}$ \\
\hline \multirow[t]{9}{*}{ Nonpharmacologic } & Exercise v. no exercise & Small & Moderate (19 RCTs) & $\begin{array}{l}\text { Yes, for patients with } \\
\text { flare-up (a temporary } \\
\text { increase in severity of } \\
\text { the ongoing } \\
\text { symptoms) }\end{array}$ & Yes \\
\hline & $\begin{array}{c}\text { Spinal manipulation v. inert } \\
\text { treatment }\end{array}$ & Small & Low (7 RCTs) & $\begin{array}{l}\text { Yes, if part of an } \\
\text { exercise program }\end{array}$ & Yes \\
\hline & $\begin{array}{c}\text { Cognitive behavioural therapy v. no } \\
\text { treatment }\end{array}$ & Moderate & Low (5 RCTs) & $\begin{array}{l}\text { Yes, if part of an } \\
\text { exercise program }\end{array}$ & Yes \\
\hline & $\begin{array}{c}\text { Behavioural (operant) therapy v. no } \\
\text { treatment }\end{array}$ & Small & Low (3 RCTs) & $\begin{array}{l}\text { Yes, if part of an } \\
\text { exercise program }\end{array}$ & Yes \\
\hline & $\begin{array}{c}\text { Multidisciplinary therapy v. usual } \\
\text { care }\end{array}$ & Moderate & Moderate (9 RCTs) & $\begin{array}{l}\text { Yes, if previous } \\
\text { treatment not effective } \\
\text { or at high risk of poor } \\
\text { outcome }\end{array}$ & Yes \\
\hline & Massage v. usual care & No effect & Low (1 RCT) & $\begin{array}{l}\text { Yes, if part of an } \\
\text { exercise program }\end{array}$ & Yes \\
\hline & Acupuncture v. placebo & Moderate & Low (9 RCTs) & Do not offer & Yes \\
\hline & Ultrasonography v. no treatment & No effect & Low (5 RCTs) & Do not offer & Do not offer \\
\hline & TENS v. sham treatment & No effect & Low (4 RCTs) & Do not offer & Do not offer \\
\hline \multirow[t]{5}{*}{ Pharmacologic } & NSAIDs v. placebo & Small & Moderate (6 RCTs) & $\begin{array}{c}\text { Yes, if safe, at lowest } \\
\text { dose and short term } \\
\text { only }\end{array}$ & $\begin{array}{c}\text { Yes, if } \\
\text { nonpharmacologic } \\
\text { options fail }\end{array}$ \\
\hline & Opioids v. placebo & Small & Moderate† (15 RCTs) ${ }^{44}$ & Do not offer & Yes, only as last resort \\
\hline & Paracetamol v. placebo & No effect & Very low† $(1 \mathrm{RCT})^{36}$ & Do not offer & Insufficient evidence \\
\hline & Tricyclic antidepressants v. placebo & No effect & Moderate (4 RCTs) & Do not offer & Do not offer \\
\hline & Benzodiazepines v. placebo & $\begin{array}{l}\text { Lower likelihood of } \\
\text { failure to improve }\end{array}$ & Low (2 RCTs) & Do not offer & Insufficient evidence \\
\hline \multirow[t]{3}{*}{ Injection therapy } & Epidural steroid injection v. placebo & No effect & Low† (2 RCTS) $)^{45}$ & Do not offer & No mention \\
\hline & $\begin{array}{l}\text { Facet joint steroid injection v. } \\
\text { placebo }\end{array}$ & No effect & Low† (2 RCTS) $)^{45}$ & Do not offer & No mention \\
\hline & $\begin{array}{l}\text { Radiofrequency denervation v. } \\
\text { sham intervention }\end{array}$ & Facet: small & Low $†\left(4\right.$ RCTs) ${ }^{14}$ & $\begin{array}{l}\text { Yes, if nonsurgical } \\
\text { treatment failed and } \\
\text { positive response to } \\
\text { medial branch block }\end{array}$ & No mention \\
\hline Surgery & Spinal fusion v. rehabilitation & No effect & Moderate† (4 RCTs) ${ }^{46}$ & $\begin{array}{c}\text { Do not offer unless as } \\
\text { part of a trial }\end{array}$ & No mention \\
\hline
\end{tabular}

Note: GRADE = Grading of Recommendations Assessment, Development and Evaluation, NSAID = nonsteroidal anti-inflammatory drug, RCT = randomized controlled trial, TENS = transcutaneous electrical nerve stimulation.

*Based on 2017 American College of Physicians guideline summary of evidence except where otherwise noted. Comparisons are to placebo, sham treatment, no treatment or usual care, and on short-term pain outcomes.

tOur summary of evidence used the GRADE approach. 
of this medicine including optimizing nonpharmacologic therapy before prescribing a trial of opioids, restricting the prescribed dosage to less than 90 morphine mg equivalents daily and providing multidisciplinary programs to patients on chronic opioid therapy who are having difficulty tapering (https://magicapp.org/app\#/guideline/2178).

\section{Other treatments}

The UK guideline recommended that surgical procedures, such as spinal fusion, should not be offered to patients with persistent low-back pain unless it is part of a RCT. ${ }^{14}$ The guideline provided clear advice on the role of epidural steroid injections: do not offer these injections to patients with persistent low-back pain. It also endorsed radiofrequency denervation for selected patients with persistent low-back pain. However, the recently published Mint randomized clinical trials ${ }^{51}$ - three high-quality trials $(n=681)$ that showed that radiofrequency denervation was not effective at reducing pain among patients with persistent low-back pain who had a positive response to a diagnostic block of the facet joint, sacroiliac joints, a combination of those areas or the intervertebral disc - has cast doubt on that recommendation. The authors of the US guideline excluded invasive treatments from their 2017 recommendations.

\section{What is the approach to a patient with radicular pain or neurogenic claudication?}

\section{Nonpharmacologic treatments}

Guideline recommendations ${ }^{14,15}$ on nonpharmacologic management of radicular pain complicating low-back pain include providing advice to stay active and suggesting an exercise program. Initial management of neurogenic claudication follows similar principles to radicular pain (Figure 1 ). These recommendations were based on a limited and inconsistent evidence base (Table 3). In 2010, a Cochrane review of two RCTs ( $n=346$ ) reported little to no effect of such advice on relief of pain. ${ }^{35} \mathrm{How}$ ever, remaining active can have other benefits, such as preventing deconditioning and improving mood. The US guideline cited

Table 3: Recent guideline recommendations for management of radicular pain of the lower back

\begin{tabular}{|c|c|c|c|c|c|}
\hline \multirow[b]{2}{*}{ Management type } & \multirow[b]{2}{*}{ Intervention } & \multirow{2}{*}{$\begin{array}{l}\text { Size of } \\
\text { effect* }\end{array}$} & \multirow[b]{2}{*}{ Quality of evidence* } & \multicolumn{2}{|c|}{ Endorsement } \\
\hline & & & & 2016 UK guideline ${ }^{14}$ & 2017 US guideline ${ }^{15}$ \\
\hline \multirow[t]{3}{*}{ Nonpharmacologic } & Exercise v. usual care & Small & Low (3 RCTs) & Yes & Yes \\
\hline & $\begin{array}{l}\text { Multidisciplinary } \\
\text { therapy v. usual care }\end{array}$ & No trials & N/A $†$ & $\begin{array}{l}\text { Yes, if previous } \\
\text { treatment not effective } \\
\text { or at risk of poor } \\
\text { prognosis }\end{array}$ & Insufficient evidence \\
\hline & $\begin{array}{l}\text { Traction } v \text {. other } \\
\text { active treatments }\end{array}$ & No effect & Low (2 RCTs) & Do not offer & Do not offer \\
\hline \multirow[t]{7}{*}{ Pharmacologic } & Diazepam v. placebo & Harm & Low (1 RCT) & No mention & Do not offer \\
\hline & $\begin{array}{c}\text { Systemic } \\
\text { corticosteroids v. } \\
\text { placebo }\end{array}$ & No effect & Moderate (6 RCTs) & No mention & Do not offer \\
\hline & Pregabalin v. placebo & No effect & High† (1 RCT $)^{27}$ & Yes & Insufficient evidence \\
\hline & $\begin{array}{l}\text { Gabapentin v. } \\
\text { placebo }\end{array}$ & Unclear & Very low† (2 RCTs) $)^{52,53}$ & Yes & Insufficient evidence \\
\hline & Opioids v. placebo & No effect & $\begin{array}{l}\text { Low† (1 crossover } \\
\text { study) }\end{array}$ & $\begin{array}{c}\text { Yes, rescue/short-term } \\
\text { only }\end{array}$ & $\begin{array}{l}\text { Yes, second-line therapy } \\
\text { only if nonpharmacologic } \\
\text { therapy fails }\end{array}$ \\
\hline & $\begin{array}{l}\text { Amitriptyline v. } \\
\text { placebo }\end{array}$ & No trials & N/A $†$ & Yes & Do not offer \\
\hline & Duloxetine v. placebo & No trials & N/A $†$ & Yes & Insufficient evidence \\
\hline Injection therapy & $\begin{array}{l}\text { Epidural steroid } \\
\text { injection v. placebo }\end{array}$ & Small & Hight (23 RCTs) $)^{54}$ & Yes & No mention \\
\hline Surgery & $\begin{array}{l}\text { Lumbar discectomy v. } \\
\text { conservative } \\
\text { management }\end{array}$ & $\begin{array}{l}\text { Discectomy } \\
\text { associated } \\
\text { with faster } \\
\text { reduction in } \\
\text { pain } \\
\text { intensity }\end{array}$ & Low† (3 RCTs) $)^{55}$ & $\begin{array}{l}\text { Yes, if nonsurgical } \\
\text { treatment failed and } \\
\text { radiologic findings are } \\
\text { consistent with sciatic } \\
\text { symptoms }\end{array}$ & No mention \\
\hline
\end{tabular}

Note: GRADE = Grading of Recommendations Assessment, Development and Evaluation, N/A = No evidence from RCTs, RCT = randomized controlled trial.

*Based on the 2017 American College of Physicians guideline summary of evidence except where otherwise noted. Comparisons are to placebo, sham treatment, no treatment or usual care, and on short-term pain outcomes.

tOur summary of evidence used the GRADE approach. 
low-quality evidence from three RCTs $(n=779)$ that exercise can have a small effect on short-term pain outcomes compared with usual care. ${ }^{15}$ Exercise may also help patients with neurogenic claudication, but evidence is limited: a 2013 Cochrane review found only one small RCT that reported that a three-week exercise program could improve leg pain compared with no treatment. ${ }^{56}$ Mechanical traction was discouraged by both guidelines: a 2013 Cochrane review found low-quality evidence from two RCTs $(n=79)$ that mechanical traction was no more effective at reducing pain than placebo traction or no treatment among patients with radicular pain. ${ }^{57}$

\section{Pharmacologic treatments}

The recent guidelines differ in their recommendations on pharmacologic management of radicular pain. Both endorse the use of opioids either as rescue medication ${ }^{14}$ or if nonpharmacologic options are unsuccessful, ${ }^{15}$ but the guidelines diverge in their endorsement of neuropathic pain medication. For example, the US guideline did not endorse anticonvulsants for radicular pain, whereas the UK guideline referred its readers to their recommendations on pharmacologic management of neuropathic pain in nonspecialist settings, ${ }^{58}$ which endorsed the use of some anticonvulsants (e.g., pregabalin and gabapentin to manage neuropathic pain)..$^{58}$ Two small RCTs (placebo controlled, $n=143$ ) of gabapentin ${ }^{52,53}$ and one high-quality RCT (placebo controlled, $n=$ 209) of pregabalin ${ }^{27}$ found that these drugs were ineffective for patients with radicular low-back pain. We found limited evidence on effective pharmacologic options for patients with neurogenic claudication: the 2013 Cochrane review ${ }^{56}$ found low- to very lowquality evidence for the efficacy of a prostaglandin analogue (limaprost alfadex) compared with an NSAID (one RCT, $n=79$ ), gabapentin compared with placebo (one RCT, $n=55$ ), and vitamin B12 compared with conservative care (one RCT, $n=152$ ).

\section{Other treatments}

The UK guideline endorsed the option of an epidural steroid injection to manage "acute or severe sciatica." However, a wellconducted systematic review and meta-analysis of 14 RCTs ( $n=$ 1316) found that while these interventions were associated with immediate reductions in pain, the benefits were small (about a 6-point reduction on a 100-point pain scale) and not sustained beyond three months compared with comprehensive rehabilitation programs. ${ }^{54}$ The UK guideline recommended that steroid injections should not be offered for treatment of neurogenic claudication related to central spinal canal stenosis; however, it did suggest that surgery may be considered for those patients with radicular pain where nonsurgical treatment has not sufficiently improved symptoms. Surgery is only indicated if diagnostic imaging finds a lesion that is consistent with the clinical presentation. The role of surgery in the management of neurogenic claudication is unclear (Box 3); a 2016 Cochrane review that evaluated the effectiveness of different types of surgery compared with different types of nonsurgical interventions in adults with symptomatic lumbar spinal stenosis found insufficient evidence to conclude whether surgical management was more effective than nonsurgical management (five RCTs, $n=643$, low-quality evidence)..$^{59}$
It may be difficult to offer minimal intervention to the patient who has substantial pain. In Appendix 1, we outline how conversations with patients might proceed to reassure and advise in these clinical situations.

\section{Who needs referral?}

\section{Referral for physical or psychological treatments}

For many patients with acute low-back pain, initial care (selfmanagement advice, reassurance, timely review) can be provided by the primary care physician (Appendix 1 ). In some emergency departments, general practices and hospital clinics, a physiotherapist or nurse may provide the initial management sessions rather than a physician, although the effectiveness of this approach has not been assessed.

The recent guidelines have recommended nonpharmacologic treatments that commonly require referral for a course of treatment (e.g., exercise, multidisciplinary rehabilitation, acupuncture, mindfulness-based stress reduction, cognitive behavioural therapies or spinal manipulation). ${ }^{14,15}$

The UK guideline recommended the use of prognostic screening tools to help physicians identify who may need referral for additional treatments, and to guide the intensity and type of management they recommend. ${ }^{14}$ Examples of validated tools include the STarT Back Screening Tool ${ }^{60}$ for patients with acute or persistent low-back pain, and the Orebro Musculoskeletal Pain Questionnaire ${ }^{61}$ and PICKUP model ${ }^{62}$ for patients with acute lowback pain. However, the risk estimates produced by the tools may be limited. For example, one systematic review of 18 cohort studies found that the prognostic accuracy of screening tools for low-back pain was, at best, modest. ${ }^{63}$ This suggests that physicians guided by the tools could misclassify a patient's prognosis (i.e., overtreat patients with a good prognosis or undertreat patients with a poor prognosis).

An alternative approach is to use the subscales of these tools to match the type of treatment to the patient. For example, tool subscales may indicate particular prognostic factors such as depressive symptomatology. These could be useful factors for physicians to discuss during a consultation and possibly address in a management plan. A limitation of this approach is that many of the available tools fail to make a distinction between prognostic factors and causal factors; targeting prognostic factors may not necessarily lead to improved outcomes. Despite this limitation, a 2011 RCT that compared the clinical effectiveness and

\section{Box 3: Unanswered questions}

- Is it possible to identify a structural cause of nonspecific lowback pain in routine clinical care, and does it matter?

- Does the content of self-management advice lead to different clinical outcomes?

- Can opioids improve recovery from acute low-back pain?

- Is surgery effective for central spinal canal stenosis?

- Which methods can help translate evidence on management of low-back pain into practice? 
cost-effectiveness of stratified primary care for back pain with usual care $(n=851)$ found that matching treatment and referral pathways to prognostic factors led to small improvements in disability compared with usual care. ${ }^{64}$ Further validation of the prognostic approach to stratified management of back pain is needed.

\section{Referral to a specialist}

Patients with clinical features of cauda equina syndrome or spinal infection require urgent referral to a spine surgeon or infectious disease specialist, respectively. A strong suspicion of metastatic disease warrants referral for definitive diagnosis. A strong suspicion of spondyloarthritis warrants referral to a rheumatologist; however, if unsure, physicians can delay the referral until after a trial of conservative treatment. Similarly, for a patient with osteoporosis who may have a stable vertebral fracture, immediate specialist referral is not warranted unless an initial trial of treatment has been unsuccessful. However, the decision to refer will depend on individual circumstances.

A thorough history and careful physical examination, rather than laboratory tests or diagnostic imaging, will help clinicians identify patients in need of specialist referral. Unfortunately, key steps in identifying serious disease from clinical evaluation are often missed. For example, one recent survey of primary care practice in Australia ${ }^{65}$ reported that only $22 \%$ of physicians performed a neurologic examination, $21 \%$ asked questions to elicit history or symptoms of infection and $12 \%$ asked questions to screen for cauda equina syndrome. These types of omissions limit ability to identify patients who must be referred for specialist review.

\section{References}

1. Global Burden of Disease Study 2013 Collaborators. Global, regional, and national incidence, prevalence, and years lived with disability for 301 acute and chronic diseases and injuries in 188 countries, 1990-2013: a systematic analysis for the Global Burden of Disease Study 2013. Lancet 2015;386:743-800.

2. Deyo RA, Weinstein JN. Low back pain. N Engl J Med 2001;344:363-70.

3. Schofield DJ, Callander EJ, Shrestha RN, et al. Labor force participation and the influence of having back problems on income poverty in Australia. Spine 2012;37:1156-63.

4. Ferreira ML, Machado G, Latimer J, et al. Factors defining care-seeking in low back pain - a meta-analysis of population based surveys. Eur J Pain 2010;14:747.e1-7.

5. Dieleman JL, Baral R, Birger M, et al. US spending on personal health care and public health, 1996-2013. JAMA 2016;316:2627-46.

6. Dagenais S, Caro J, Haldeman S. A systematic review of low back pain cost of illness studies in the United States and internationally. Spine J 2008;8:8-20.

7. Deyo RA, Mirza SK, Turner JA, et al. Overtreating chronic back pain: time to back off? J Am Board Fam Med 2009;22:62-8.

8. Institute of Medicine (US) Committee on Quality of Health Care in America. Crossing the quality chasm. A new health system for the 21st century. Washington (DC): National Academies Press; 2001.

9. Abdel Shaheed C, Maher CG, Williams KA, et al. Efficacy, tolerability, and dosedependent effects of opioid analgesics for low back pain: a systematic review and meta-analysis. JAMA Intern Med 2016;176:958-68.

10. Jarvik JG, Gold LS, Comstock BA, et al. Association of early imaging for back pain with clinical outcomes in older adults. JAMA 2015;313:1143-53.

11. Mannion AF, Brox JI, Fairbank JC. Consensus at last! Long-term results of all randomized controlled trials show that fusion is no better than non-operative care in improving pain and disability in chronic low back pain. Spine $J$ 2016;16:588-90.

12. Williams CM, Maher CG, Hancock MJ, et al. Low back pain and best practice care: a survey of general practice physicians. Arch Intern Med 2010;170:271-7.

13. Runciman WB, Hunt TD, Hannaford NA, et al. CareTrack: assessing the appropriateness of health care delivery in Australia. Med J Aust 2012;197:100-5.
14. National Institute for Health and Care Excellence (NICE). Low back pain and sciatica in over 16s: assessment and management. NICE guideline [NG59]. London (UK): NICE; 2016.

15. Qaseem A, Wilt TJ, McLean RM, et al.; Clinical Guidelines Committee of the American College of Physicians. Non-invasive treatments for acute, subacute, and chronic low back pain: a clinical practice guideline from the American College of Physicians. Ann Intern Med 2017;166:514-30.

16. Maher C, Underwood M, Buchbinder R. Non-specific low back pain. Lancet 2017;389:736-47.

17. Koes BW, van Tulder MW, Thomas S. Diagnosis and treatment of low back pain. BMJ 2006;332:1430-4.

18. Henschke N, Maher CG, Refshauge KM, et al. Prevalence of and screening for serious spinal pathology in patients presenting to primary care with acute low back pain. Arthritis Rheum 2009;60:3072-80.

19. Williams CM, Henschke N, Maher CG, et al. Red flags to screen for vertebral fracture in patients presenting with low-back pain. Cochrane Database Syst Rev 2013;(1):CD008643.

20. Poddubnyy D, van Tubergen A, Landewé R, et al. Assessment of SpondyloArthritis international Society (ASAS). Development of an ASAS-endorsed recommendation for the early referral of patients with a suspicion of axial spondyloarthritis. Ann Rheum Dis 2015;74:1483-7.

21. Lederle FA, Simel DL. The rational clinical examination. Does this patient have abdominal aortic aneurysm? JAMA 1999;281:77-82.

22. Atlas SJ, Deyo RA. Evaluating and managing acute low back pain in the primary care setting. J Gen Intern Med 2001;16:120-31.

23. Kent $\mathrm{P}$, Keating J. Do primary-care clinicians think that nonspecific low back pain is one condition? Spine 2004;29:1022-31.

24. Kent $\mathrm{P}$, Keating JL. Classification in nonspecific low back pain: What methods do primary care clinicians currently use? Spine 2005;30:1433-40.

25. Hancock MJ, Maher CG, Latimer J, et al. Systematic review of tests to identify the disc, SIJ or facet joint as the source of low back pain. Eur Spine J 2007;16: 1539-50.

26. Mathieson S, Maher CG, Terwee CB, et al. Neuropathic pain screening questionnaires have limited measurement properties. A systematic review. J Clin Epidemiol 2015;68:957-66.

27. Mathieson S, Maher CG, McLachlan AJ, et al. Trial of pregabalin for acute and chronic sciatica. N Engl J Med 2017;376:1111-20.

28. Manchikanti L, Pampati V, Singh V, et al. Assessment of the escalating growth of facet joint interventions in the Medicare population in the United States from 2000 to 2011. Pain Physician 2013;16:E365-78.

29. Chou R, Qaseem A, Owens DK, et al.; Clinical Guidelines Committee of the American College of Physicians. Diagnostic imaging for low back pain: advice for highvalue health care from the American College of Physicians. Ann Intern Med 2011;154:181-9.

30. Dagenais S, Tricco AC, Haldeman S. Synthesis of recommendations for the assessment and management of low back pain from recent clinical practice guidelines. Spine J 2010;10:514-29.

31. Harding IJ, Davies E, Buchanan E, et al. The symptom of night pain in a back pain triage clinic. Spine 2005;30:1985-8.

32. Henschke N, Maher CG, Ostelo RW, et al. Red flags to screen for malignancy in patients with low back pain. Cochrane Database Syst Rev 2013;(2):CD008686.

33. George SZ, Beneciuk JM, Bialosky JE, et al. Development of a review-of-systems screening tool for orthopaedic physical therapists: results from the Optimal Screening for Prediction of Referral and Outcome (OSPRO) cohort. J Orthop Sports Phys Ther 2015;45:512-26.

34. Hoffmann TC, Del Mar CB, Strong J, et al. Patients' expectations of acute low back pain management: implications for evidence uptake. BMC Fam Pract 2013;14:7.

35. Dahm KT, Brurberg KG, Jamtvedt G, et al. Advice to rest in bed versus advice to stay active for acute low-back pain and sciatica. Cochrane Database Syst Rev 2010;(6):CD007612.

36. Machado GC, Maher CG, Ferreira PH, et al. Efficacy and safety of paracetamol for spinal pain and osteoarthritis: systematic review and meta-analysis of randomised placebo controlled trials. BMJ 2015;350:h1225.

37. da C Menezes Costa L, Maher CG, Hancock MJ, et al. The prognosis of acute and persistent low-back pain: a meta-analysis. CMAJ 2012;184:E613-24.

38. Paige NM, Miake-Lye IM, Booth MS, et al. Association of spinal manipulative therapy with clinical benefit and harm for acute low back pain: systematic review and meta-analysis. JAMA 2017;317:1451-60.

39. Traeger AC, Hübscher M, Henschke N, et al. Effect of primary care-based education on reassurance in patients with acute low back pain: systematic review and meta-analysis. JAMA Intern Med 2015;175:733-43.

40. French SD, Cameron M, Walker BF, et al. A Cochrane review of superficial heat or cold for low back pain. Spine 2006;31:998-1006.

41. Steffens D, Maher CG, Pereira LS, et al. Prevention of low back pain: a systematic review and meta-analysis. JAMA Intern Med 2016;176:199-208. 
42. Machado GC, Maher CG, Ferreira PH, et al. Non-steroidal anti-inflammatory drugs for spinal pain: a systematic review and meta-analysis. Ann Rheum Dis 2017;76:1269-78.

43. Abdel Shaheed C, Maher CG, Williams KA, et al. Efficacy and tolerability of muscle relaxants for low back pain: systematic review and meta-analysis. Eur $J$ Pain 2017;21:228-37.

44. Chaparro LE, Furlan AD, Deshpande A, et al. Opioids compared to placebo or other treatments for chronic low-back pain. Cochrane Database Syst Rev 2013;(8):CD004959.

45. Staal JB, de Bie R, de Vet HC, et al. Injection therapy for subacute and chronic low-back pain. Cochrane Database Syst Rev 2008;(3):CD001824.

46. Chou R, Baisden J, Carragee EJ, et al. Surgery for low back pain: a review of the evidence for an American Pain Society Clinical Practice Guideline. Spine 2009;34:1094-109.

47. Saragiotto BT, Maher CG, Traeger AC, et al. Dispelling the myth that chronic pain is unresponsive to treatment. Br J Sports Med 2017;51:986-8.

48. Hill JC, Whitehurst DG, Lewis M, et al. Comparison of stratified primary care management for low back pain with current best practice (STarT Back): a randomised controlled trial. Lancet 2011;378:1560-71.

49. Dowell D, Haegerich TM, Chou R. CDC guideline for prescribing opioids for chronic pain - United States, 2016. JAMA 2016;315:1624-45.

50. Busse JW, Craigie S, Juurlink DN, et al. Guideline for opioid therapy and noncancer pain. CMAJ 2017;189:659-66.

51. Juch JNS, Maas ET, Ostelo RWJG, et al. Effect of radiofrequency denervation on pain intensity among patients with chronic low back pain: the Mint randomized clinical trials. JAMA 2017;318:68-81.

52. Yildirim K, Deniz O, Gureser G, et al. Gabapentin monotherapy in patients with chronic radiculopathy: the efficacy and impact on life quality. J Back Musculoskelet Rehabil 2009;22:17-20.

53. Atkinson JH, Slater MA, Capparelli EV, et al. A randomized controlled trial of gabapentin for chronic low back pain with and without a radiating component. Pain 2016;157:1499-507.
54. Pinto RZ, Maher CG, Ferreira ML, et al. Epidural corticosteroid injections in the management of sciatica: a systematic review and meta-analysis. Ann Intern Med 2012;157:865-77.

55. Gibson JN, Waddell G. Surgical interventions for lumbar disc prolapse. Cochrane Database Syst Rev 2007;(2):CD001350.

56. Ammendolia C, Stuber KJ, Rok E, et al. Nonoperative treatment for lumbar spinal stenosis with neurogenic claudication. Cochrane Database Syst Rev 2013; (8):CD010712

57. Wegner I, Widyahening IS, van Tulder MW, et al. Traction for low-back pain with or without sciatica. Cochrane Database Syst Rev 2013;(8):CD003010.

58. National Institute for Health and Care Excellence (NICE). Neuropathic pain in adults: pharmacological management in non-specialist settings. Clinical guideline [CG96]. London (UK): NICE; 2010.

59. Zaina F, Tomkins-Lane C, Carragee E, et al. Surgical versus nonsurgical treatment for lumbar spinal stenosis. Spine 2016;41:E857-68.

60. Hill JC, Dunn KM, Lewis M, et al. A primary care back pain screening tool: identifying patient subgroups for initial treatment. Arthritis Rheum 2008;59:632-41.

61. Linton SJ, Halldén K. Can we screen for problematic back pain? A screening questionnaire for predicting outcome in acute and subacute back pain. Clin $\mathrm{J}$ Pain 1998;14:209-15.

62. Traeger AC, Henschke N, Hubscher M, et al. Estimating the risk of chronic pain: development and validation of a prognostic model (PICKUP) for patients with acute low back pain. PLoS Med 2016;13:e1002019.

63. Karran EL, McAuley JH, Traeger AC, et al. Can screening instruments accurately determine poor outcome risk in adults with recent onset low back pain? A systematic review and meta-analysis. BMC Med 2017;15:13.

64. Hill JC, Whitehurst DG, Lewis M, et al. Comparison of stratified primary care management for low back pain with current best practice (STarT Back): a randomised controlled trial. Lancet 2011;378:1560-71.

65. Ramanathan SA, Hibbert PD, Maher CG, et al. Care Track: towards appropriate care for low back pain. Spine 2017;42:E802-9.

\section{Competing interests: None declared.}

This article has been peer reviewed.

Affiliations: School of Public Health (Traeger, Maher), Sydney Medical School, University of Sydney, Sydney, Australia; Monash Department of Clinical Epidemiology (Buchbinder), Cabrini Institute, Malvern, Australia; Department of Epidemiology and Preventive Medicine (Buchbinder), School of Public Health and Preventive Medicine, Monash University, Melbourne, Australia; Whitlam Orthopaedic
Research Centre (Harris), Ingham Institute for Applied Medical Research, South Western Sydney Clinical School, University of New South Wales, Liverpool, Australia

Contributors: All of the authors contributed to the conception and design of the work. Adrian Traeger wrote the first draft of the manuscript. All of the authors revised the manuscript critically for important intellectual content, gave final approval of the version to be published and agreed to be accountable for all aspects of the work.
Funding: Adrian Traeger is supported by a National Health and Medical Research Council (NHMRC) research program grant. Rachelle Buchbinder is supported by an NHMRC Senior Principal Research Fellowship. Chris Maher is supported by an NHMRC Principal Research Fellowship.

Correspondence to: Adrian Traeger, adrian.traeger@sydney.edu.au 